\title{
Sobre a luta, as políticas públicas e a emancipação: o caso do projeto do assentamento Pirituba II, em Itaberá e Itapeva - SP
}

On action, public policy and emancipation: the case settlement project II Pirituba in Itaberá and Itapeva-SP

\section{Ana Terra Reis*}

\begin{abstract}
Resumo:
O presente artigo está dividido em seis partes, incluindo a introdução e as considerações finais. Buscou-se realizar, em um primeiro momento, uma discussão acerca do avanço do modo de produção capitalista no campo brasileiro, a partir dos paradigmas da questão agrária e do capitalismo agrário. Na segunda sessão, discutiuse sobre o papel do Estado e das políticas públicas; na terceira e quarta sessões, foram apresentados os elementos da luta pela terra e a consolidação do Projeto de Assentamento Pirituba II, sob a ótica da cooperação e da criação de resistências pelo campesinato.
\end{abstract}

Palavras Chave: Capitalismo, Campesinato, Estado, Reforma agrária.

\begin{abstract}
:
This article is divided into six parts, counting the introduction and closing remarks. In order to make at first a discussion of the progress of capitalist production in the Brazilian countryside, from the paradigms of the agrarian question and the agrarian capitalism. In the second session presents a discussion about the role of government and public policy, in the third and fourth session we present details of the struggle for land consolidation and Settlement Project Pirituba II from the perspective of cooperation and the creation of resistances peasantry.
\end{abstract}

Keywords: Capitalism, Peasantry, State, Agrarian reform.

\section{Introdução}

Fazer uma avaliação das políticas públicas nos territórios camponeses não é uma tarefa fácil. Muito já se teorizou sobre o papel do Estado e dos Movimentos Sociais e, ao que parece, a conclusão mais próxima dos interesses da classe trabalhadora afirma que o

\footnotetext{
* Doutoranda do Programa de Pós Graduação em Geografia pela FCT/UNESP, militante do MST e participante do Centro de Estudos em Geografia do Trabalho - CEGET - Email: anaterrareis@gmail.com
} 
Estado é mantenedor das relações capitalistas de produção, pois beneficia o capital em detrimento da emancipação social. É a esfera política, influenciada pela esfera econômica, que funciona para a dominação da esfera social.

Embora as conclusões mais pessimistas não apontem uma saída, pois afirmam que a opressão da lógica perversa desse sistema hegemônico permanecerá até que se consiga uma transformação profunda da sociedade, algumas experiências recentes se destacam como possibilidades de se amenizar, ainda que não de resolver, a exploração do capital sobre homens e mulheres que vivem de seu trabalho. É uma realidade contraditória, como qualquer outra.

Quando se trata dessa realidade no âmbito do campo, há muitos determinantes. A realidade também mostra que o capital assumiu e se apropriou de outras formas de reprodução, com o intuito de apresentar sua chibata e evidenciar que é preciso ter discernimento para não transformar as conquistas da classe trabalhadora em políticas conciliatórias com a ordem estabelecida.

Resta tentar, assim, a teorização das práticas e buscar entender o papel de cada um na luta por uma sociedade diferente, por meio da qualificação das demandas e da avaliação dos reflexos das ações humanas no mundo do trabalho, ou seja, na vida daqueles que tentam vislumbrar uma nova forma de posicionar-se frente aos desafios da emancipação da classe trabalhadora.

\section{O avanço do modo de produção capitalista no campo brasileiro}

Os territórios camponeses são analisados, neste estudo, com o objetivo de se desvendar as relações de poder que afetam a vida dos trabalhadores do campo, alterando as relações de produção por meio da separação entre produtor e meios de produção. Neste sentido, Raffestin (1993) afirma que toda construção da realidade é um instrumento de poder.

O território é revelado pelas relações de poder que o envolvem, assim, para entendêlo é necessário que se reflita sobre as estruturas de mando que determinam o tecido social. Para tal, o território deve ser entendido como movimento, como processo de realização desrealização, territorialização - desterritorialização - reterritorialização, o que acaba por evidenciar os conteúdos da luta de classes (THOMAZ JUNIOR, 2004). 
Para tanto, o debate sobre a questão deve ter início pela análise das relações de produção que estão sendo desenvolvidas no campo, dimensionando como se dão as dinâmicas produtivas.

Nas palavras de Thomaz Junior (2002, p. 5):

[...] há um conjunto de relações e de mediações específicas ao mundo do trabalho que nos permitem compreender a magnitude e a escala do processo de dominação do capital, fundado na busca constante da elevação dos índices de produtividade, dos melhores resultados econômicos e também nos procedimentos destinados ao exercício sempre refeito da gestão e controle do trabalho em todas as instâncias da vida da classe-que-vive-do-trabalho, que são redefinidos pelos referenciais da reestruturação produtiva do capital.

O debate de classes perpassa pela concepção de explorados e exploradores e, neste sentido, o campesinato é visto como classe frente à resistência histórica que desempenha em oposição à classe dominante, representada pelos proprietários privados, de terras ou de meios de produção. Segundo Kautsky (1980), o camponês é um trabalhador, pois não vive do produto de sua empresa, mas do produto de sua própria atividade.

Compreende-se os trabalhadores rurais assentados como camponeses, ou como classe-que-vive-do-trabalho, uma vez que estão subsumidos à lógica dos projetos de desenvolvimento, no sentido do avanço do sistema metabólico do capital, que impõe a lógica de produção de mercadorias a todos os que vivem de seu trabalho.

Revela-se, assim, o trabalho estranhado na agricultura, uma vez que os agricultores produzem mercadorias que estão além de suas necessidades primeiras, além da compreensão acerca do trabalho desempenhado e, por fim, além de sua relação com a própria natureza. Nesse sentido, conforme Marx (2004, p. 153-154):

Se o produto do trabalho não pertence ao trabalhador, um poder estranho [que] está frente a ele, então isto só é possível pôr [o produto do trabalho] pertencer a um outro homem fora o trabalhador. Se ele se relaciona, portanto, com o produto do seu trabalho, enquanto objeto estranho, hostil, poderoso, dele independente, então se relaciona com ele de forma tal que um outro homem, estranho a ele, inimigo, poderoso, dele independente é o senhor deste objeto.

Assim, buscou-se compreender de que forma o metabolismo do capital, a partir da lógica do mercado, vêm determinando a produção e a reprodução da vida social do campesinato, seja pela orientação da produção a partir da imposição de pacotes tecnológicos, seja pela apropriação dos produtos do trabalho. Neste contexto, é 
importante analisar, ainda, as formas de apropriação capitalista do trabalho camponês tratadas por Kautsky (1980, p. 24):

Se se deseja estudar a questão agrária segundo o método de Marx, não se deve equacionar apenas o problema de saber se a pequena exploração tem ou não futuro na agricultura. Deve-se, ao contrário, pesquisar todas as transformações experimentadas por esta última no decurso do regime de produção capitalista. Deve-se pesquisar se e como o capital se apodera da agricultura, revolucionandoa, subvertendo as antigas formas de produção e de propriedade, criando a necessidade de novas formas.

No Brasil, os princípios de preservação da grande propriedade fundiária, que pratica a monocultora voltada para o mercado externo, explora os recursos naturais e, principalmente, expropria os trabalhadores, vêm se transformando ao longo dos séculos, consolidando o capital e alterando, rapidamente, a condição de vida dos trabalhadores/agricultores.

A história agrária brasileira é marcada por duas concepções de desenvolvimento: uma pautada na hegemonia do modo de produção capitalista e outra marcada pela resistência daqueles que vivem do seu trabalho. A interpretação acerca do avanço do modo de produção capitalista, no campo brasileiro, passa por dois processos metodológicos, denominados paradigmas, por Fernandes, Welch e Gonçalves (2011, p. 17). Segundo os autores: "Os paradigmas representam as visões de mundo, que contêm interesses e ideologias, desejos e determinações, que se materializam através de políticas públicas nos territórios de acordo com as pretensões das classes sociais." (FERNANDES; WELCH; GONÇALVES, 2011, p. 17).

Com o intuito de contribuir para a compreensão dos paradigmas propostos, Fernandes, Welch e Gonçalves (2011, p. 18) definem o paradigma da questão agrária como o que se volta à interpretação das lutas de classes que ocorrem na disputa pelos territórios:

O paradigma da questão agrária tem como ponto de partida as lutas de classes para explicar as disputas territoriais e suas conflitualidades na defesa de modelos de desenvolvimento que viabilizem a autonomia dos camponeses. Entende que os problemas agrários fazem parte da estrutura do capitalismo, de modo que a luta contra o capitalismo é a perspectiva de construção de outra sociedade [...].

Em relação ao paradigma do capitalismo agrário, os autores explicitam que:

[...] as desigualdades geradas pelas relações capitalistas são um problema conjuntural que pode ser superado por meio de políticas que possibilitem a 
"integração" do campesinato ou "agricultor de base familiar" ao mercado capitalista (FERNANDES; WELCH; GONÇALVES, 2011, p. 18).

A possibilidade de superação das desigualdades históricas por meio da "integração" tem se mostrado inviável, pois o capital se reproduz a partir da apropriação e da recriação das formas de dominação do trabalho. Para aprofundar o debate acerca dessas relações e mediações que possibilitam a reprodução do modo de produção capitalista e para demonstrar a inviabilidade de se discutir a suposta superação da realidade excludente e degradante, pela ótica do paradigma do capitalismo agrário, é necessário observar a evolução do capital na agricultura e as formas encontradas pela classe trabalhadora para resistir às transformações.

Embora o capital internacional, muitas vezes, fictício, tenha proliferado por todos os segmentos da economia, aliando-se ao latifúndio e à elite agrária brasileira e articulando o agronegócio em diversas dimensões da vida no campo, a classe-que-vive do trabalho continua travando lutas pela Reforma Agrária e recriando o campesinato enquanto classe que resiste no campo.

É por isso que a luta pela terra desenvolvida pelos camponeses no Brasil, é uma luta específica, moderna, característica particular do século XX. Dessa forma, o século $X X$, foi um século por excelência na formação e consolidação do campesinato brasileiro enquanto classe social. É por isso, que este camponês não é um camponês que na terra, entrava o desenvolvimento das forças produtivas impedindo, portanto, o desenvolvimento do capitalismo no campo. Ao contrário, ele praticamente nunca teve acesso a terra, é, pois, um desterrado, um sem-terra que luta para conseguir o acesso a terra (OLIVEIRA, 2007, p. 152).

A busca por uma visão totalitária, que integre todas classes numa perspectiva de desenvolvimento, ou melhor, de crescimento econômico, é uma visão equivocada, pois ignora as contradições da sociedade de classes, característica do modo de produção capitalista.

\section{O papel do estado e as políticas públicas}

Torna-se importante, neste ponto, analisar qual a origem do Estado e quais os determinantes na formação do mesmo, pois este debate pode servir como subsídio para se compreender a atuação e as mediações existentes no interior da sociedade, sob o modo de produção capitalista. 
Como afirma Engels, citado por Lênin (2003, p. 24):

O Estado não é, de forma alguma, uma força imposta, do exterior, à sociedade. Não é, tampouco, "a realidade da ideia moral", nem "a imagem e a realidade da razão" como pretende Hegel. É um produto da sociedade numa certa fase de seu desenvolvimento. É a confissão de que a sociedade se embaraçou numa insolúvel contradição interna, se dividiu em antagonismos inconciliáveis de que não pode desvencilhar-se. Essa força, que sai da sociedade, ficando porém, acima dela e se afastando cada vez mais, é o Estado.

Esta afirmação é corroborada por diversos autores que se dedicaram ao estudo do papel do Estado no sentido de dominação de classe. Segundo Berberoglu (2011) e Petras (2011), o estado é um lugar de luta de classes e uma fonte fundamental de poder de classe, um instrumento multifuncional exercido pela classe dominante em seu próprio interesse e um meio para manter a ordem e reconciliar as distintas formas do conflito social.

Holfing (2001) destaca que as políticas sociais comportam-se como formas de interferência do Estado, pois visam à manutenção das relações sociais de determinada formação social. Portanto, assumem "feições" diferentes em diferentes sociedades e diferentes concepções de Estado. Sendo assim, geralmente, a perspectiva destas políticas é não se estabelecerem, a priori, na direção de um patamar de redução de desequilíbrios, mas vinculadas à ideia de desenvolvimento econômico e de articulação dos sujeitos sociais em uma dada sociedade de mercado. Para Thomaz Junior (2009, p. 116):

[...] a lógica expansiva do capital encontra limites internos à sua própria racionalidade, pois não tem autonomia e capacidade para estabelecer estratégias de longo prazo, com o propósito de sustentar a acumulação ampliada. Isso só se faz por meio da coerção extra econômica exemplarmente exercida pelo Estado, que garante ao capitalista privado as condições básicas para o desenvolvimento tecnológico, a regulamentação do sistema financeiro internacional, mantendo lucrativas as atividades produtivas. A prova mais marcante dessa condição está visível na constituição do Estado de Bem-Estar Social, logo após o fim da Segunda Guerra Mundial.

As formas que os diferentes governos têm buscado para superar as visões paradigmáticas não resultam em respostas satisfatórias, uma vez que a estratégia de desenvolvimento de políticas públicas enfrenta resistências:

[...] se o governo enfrenta resistência do agronegócio é porque os ministérios estão dominados pelo paradigma do capitalismo agrário. Por conta disso as políticas para o desenvolvimento desses territórios não acontecem de forma efetiva o que possibilita ao capital ser hegemônico determinando as relações 
sociais e econômicas que homogeneízam as paisagens rurais pela monótona monocultura (FERNANDES; WELCH; GONÇALVES, 2011. p.32).

Sendo assim, o Estado tem sido e é essencial para o êxito do sistema metabólico do capital e para a defesa das relações sociais de produção dominantes. Segundo Petras e Voltmeyer (2003), em cada forma específica da formação agrícola, o Estado tem sido uma peça chave na fundação, extensão, reprodução e transformação do sistema capitalista, de modo a beneficiar determinadas classes - no Brasil, sempre os grandes latifundiários - em prejuízo de outras - principalmente, dos trabalhadores e camponeses.

Em que pesem todas as iniciativas e debates feitos em torno da implementação de políticas públicas no campo, o que se percebe é a continuidade na imposição de pacotes tecnológicos à agricultura camponesa, condenada à perda de sua autonomia na produção e à subsunção à lógica do mercado, com a clara pretensão de ocultar a dualidade de projetos de desenvolvimento que persistem no campo.

Observar esta realidade a partir do chão onde se pisa, sem falsear números, e dialogar, constantemente, com as famílias assentadas, leva à percepção de que a hegemonia no interior do Estado continua sendo da aristocracia agrária brasileira, agora aliada às transnacionais do agronegócio. Essa hegemonia também passa pela mídia, que tem tido um papel fundamental na criminalização dos movimentos sociais e na divulgação da ideologia de um mundo rural moderno e sem conflitos, onde tudo pode ser resolvido a partir da inserção no mercado.

O que resta é a necessidade de apropriação política, por parte dos movimentos sociais, de cada uma das reivindicações que ainda persistem, por meio da organização das famílias camponesas para avançar na construção da autonomia em seus territórios. Esta autonomia se refere à aproximação dos trabalhadores em relação aos meios de produção. No caso dos assentamentos de Reforma Agrária, tal fato se manifesta a partir da organização de um novo modelo produtivo, pautado na soberania alimentar enquanto estratégia de superação do estranhamento na produção agrícola, imposto pelo agronegócio.

\section{A luta pela terra como alternativa de emancipação social}


Por outro lado, o processo histórico mostra que o desenvolvimento do modo de produção capitalista acaba por desenvolver resistências e conflitos constantes:

\begin{abstract}
A desigualdade gerada e gerida pelo capitalismo não produz apenas riqueza, pobreza e miséria. Ela também desenvolve o conflito, porque as pessoas não são objetos que compõem unidades de produção. São sujeitos históricos que resistem a exploração e a expropriação, bem como querem compartir os resultados da produção de seu trabalho. [...] Um conflito por terra é um confronto entre classes sociais, entre modelos de desenvolvimento, por territórios (FERNANDES; WELCH; GONÇALVES 2011, p. 26).
\end{abstract}

Desse modo, ainda que tal realidade avassaladora esteja posta, existem também as resistências protagonizadas pela classe trabalhadora. Historicamente, a sobrevivência da classe camponesa tem sido responsável pela luta por territórios para que seja possível sua reprodução social. Essas lutas são chamadas, por Fernandes (2008, p. 2), de conflitualidades:

\begin{abstract}
A questão agrária sempre esteve relacionada com os conflitos por terra. [...]. 0 enfrentamento é um momento do conflito para compreendê-lo em seu movimento utilizamos o conceito de conflitualidade. A conflitualidade é um processo constante alimentado pelas contradições e desigualdades do capitalismo. O movimento da conflitualidade é paradoxal ao promover [...] a territorialização-desterritorialização-reterritorialização de diferentes relações sociais. [...]. São processos de desenvolvimento territorial rural formadores de diferentes organizações sociais.
\end{abstract}

As organizações que foram sendo forjadas e transformadas na história brasileira, desde a resistência indígena e quilombola até as Ligas Camponesas e, mais recentemente, os movimentos sociais ligados à Via Campesina, amadureceram os processos de luta, enfrentaram limites e desenharam novos desafios:

Ao longo dos anos, na formação da identidade política, sujeitos e organizações alteram seus entendimentos sobre a natureza paradigmática da luta. Todavia, por ser uma questão estrutural, os conflitos pela terra têm se mantido constantes. Luta após luta, as classes subalternas tentam resistir na terra, ocupar a terra, ao mesmo tempo em que compreende o alinhamento entre o Estado e latifundiários que sempre mantiveram a estrutura fundiária concentrada (FERNANDES; WELCH; GONÇALVES, 2011, p. 18).

Neste sentido, mesmo com o avanço do capital, com seu caráter concentrador, as conflitualidades continuam sendo geradas:

[...] a questão agrária gera continuamente conflitualidade. Porque é movimento de destruição e recriação de relações sociais. [...] A conflitualidade é o processo 
de enfrentamento perene que explicita o paradoxo das contradições e as desigualdades do sistema capitalista, evidenciando a necessidade do debate permanente [...] a respeito do controle político e dos modelos de desenvolvimento (FERNANDES, 2008, p. 5).

Isso significa que, mesmo após a conquista da terra, a luta pela emancipação permanece, pois o que determina a conquista do território são as relações de poder nele estabelecidas, determinadas, por sua vez, pelo papel desempenhado pelo capital, pelo Estado, pelos camponeses e por suas organizações.

A territorialização do capital em uma região e suas diferentes formas de intensidade, socializa e expropria, incorpora e exclui, não somente os camponeses, mas também os próprios capitalistas. E essa não é somente uma questão de 'competitividade' ou 'eficiência', mas é um processo complexo por sua amplitude que, sem dúvidas, contém, sobretudo a conflitualidade (FERNANDES, 2008, p. 19).

Este novo perfil de conflitualidade, expresso pelas formas de apropriação da renda propiciada pela atividade na terra, define-se pelo controle político dos territórios e pela autonomia dos agricultores assentados:

Os conflitos, portanto, envolvem privilégios, interesses e direitos, reivindicações e luta. A instituição competente para solucionar esse conflito é o Estado. E os governos têm dado diferentes respostas para a questão da terra. [...]. A ocupação de terra é uma afronta aos princípios da sociedade capitalista. Mas, ao mesmo tempo também é uma forma de desenvolvimento do capitalismo, porque as áreas ocupadas quando transformadas em assentamentos, tornam-se propriedades familiares, que produzem a renda apropriada na sua maior parte pelos capitalistas (FERNANDES, 2008, p.46-47).

Novamente, vê-se a contradição exposta no papel cumprido pelo Estado, após a luta e a conquista da terra.

Essas propriedades da contradição da questão agrária compõem a conflitualidade. Elas estão presentes nas disputas paradigmáticas entre a Questão Agrária e o Capitalismo Agrário, nos processos de espacialização e de territorialização e nos projetos de políticas públicas criados pelo Estado. Urge ao campesinato assumir de fato seu lugar na história, e ao Estado democrático o papel de garantir a participação efetiva dos camponeses na construção de projetos de desenvolvimento da agricultura camponesa (FERNANDES, 2008, p. 25).

O mundo do trabalho sofreu alterações, a produção transformou-se, as tecnologias de comunicação modernizaram-se, todas as coisas da vida material parecem ter ganhado uma fluidez e uma rapidez que, muitas vezes, fogem da capacidade de interpretação 
humana, entretanto, há a necessidade de se continuar a pensar em possibilidades de transformação da realidade. Assim como as forças ligadas à classe trabalhadora e aos movimentos sociais não têm respostas para estas rápidas transformações, o capital também não as tem. Nas palavras de Mèszaros (2011, p. 77):

\begin{abstract}
Onde quer que olhemos, perceberemos que aquilo que parece ser - e é sonoramente propagandeado como - uma sólida solução duradoura, mais cedo ou mais tarde desfaz-se em pó. Por exemplo, tentemos simplesmente vistoriar em nossa mente a história efêmera dos "milagres econômicos" que se sucederam nas décadas pós-guerra.
\end{abstract}

\title{
A consolidação dos territórios camponeses: o caso dos assentamentos da
}

\section{fazenda Pirituba}

A história da luta pela terra na Região Sudoeste de São Paulo demonstra as contradições geradas devido ao avanço do capital no campo, à desterritorialização dos camponeses e ao surgimento dos movimentos sociais, que se organizaram para a concretização dos assentamentos, em um processo de reterritorialização.

O movimento camponês pressupõe um estado de contestação. Os ideais e as práticas contestantes são relevantes, pois constituem uma interpretação divergente da ordem estabelecida ou do "novo", que desestrutura as relações existentes (OLIVEIRA, 1998, p. 74). É neste processo de expropriação que o camponês, em busca de sua reprodução, recusase a se inserir em outra forma de sociedade, ou seja, recusa-se a se "descampenisar", assim, organiza-se e resiste (BOMBARDI, 2005, p. 648). Essa resistência é uma resistência de classe.

De acordo com Bombardi (2005), a discussão da trajetória da Fazenda Pirituba traz a possibilidade de se interpretar a Lei de Revisão Agrária e seu significado político e territorial. A Fazenda Pirituba, localizada entre os municípios de Itaberá e Itapeva, com área de 17.420 hectares, foi palco de grilagem de terra, corrupção de funcionários públicos e de conflitos entre camponeses e grileiros.

Para entender esta história, faz-se necessário compreender o contexto político que moldava o território da Pirituba. Para Bombardi (2005, p. 576), essa área tem uma longa e conflituosa história, que remonta ao primeiro governo de Adhemar de Barros, entre 1947 e 1951, em São Paulo: “a fazenda passou ao patrimônio do Estado em 1949, quando uma empresa chamada Companhia Angatuba não conseguiu saldar dívidas hipotecadas". 
É importante ressaltar que, na fazenda Pirituba, havia famílias de camponesesrendeiros, em grande parte originárias das imediações, que tomavam em arrendamento parte dessas terras. A proposta de incentivar o cultivo de trigo, especificamente, nessa região, surgiu por parte do governo do estado, com o objetivo de diminuir a dependência do Brasil em relação aos países europeus exportadores desse produto, pois estas estavam envolvidos na II Guerra Mundial.

Veiga (1990 apud BOMBARDI, 2005) afirma:

O governador Adhemar de Barros projetou, então, instalar ali um polo destinado à ampliação da lavoura do trigo. Para isso entregou a fazenda a um agrônomo italiano chamado de Lino Vicenzi. Este deveria trazer famílias da Itália que receberiam todo o apoio do Estado no âmbito de uma grande campanha pelo abastecimento interno de trigo.

A condução do processo de implantação do cultivo de trigo pelo agrônomo deixou de lado esses camponeses "rendeiros", a fim de garantir que os migrantes italianos pudessem se apropriar das terras sem empecilhos. Iniciou-se, nesse momento, o primeiro conflito pela grande área de terra pública que era a Fazenda Pirituba.

"Lino Vincezi geriu essa área como se fosse sua propriedade, condicionando o cultivo à extração da renda da terra. Assim, passou a receber ilicitamente, a renda da terra de uma área que era sabidamente pública." (BOMBARDI, 2005, p. 584).

A partir desses arrendamentos irregulares, foram se apropriando da terra grandes pecuaristas ou boiadeiros, que pagavam ao funcionário público pelo direito de utilizar a área, até que:

Em 1962, o governador Carvalho Pinto requereu a devolução da posse da fazenda para destiná-la aos planos de colonização baseados na recentíssima Lei de Revisão Agrária. [...] e logo percebe que os tais grandes arrendatários de pastos não tinham a intenção de perder o privilégio. Entre os que resistiram estavam, por coincidência, três filhos de Vincezi que, a despeito da gorda indenização recebida pelo pai, permaneceram ocupando as terras (VEIGA, 1990 apud BOMBARDI, 2005).

O Estado acionou as formas legais de despejo contra os ocupantes irregulares, que ainda permaneciam na área, o que deu início a um conflito entre o Estado e os grandes exploradores da área da Fazenda, que encontravam brechas para resistir ao despejo.

Dada esta realidade, que foi um marco da questão agrária no Estado de São Paulo, o governo foi obrigado a criar mecanismos para conter o processo de apropriação indevida 
de terras públicas e a corrupção por parte de seu representante. No ano de 1962, a ARA (Assessoria de Revisão Agrária) deu início a um estudo sobre a fazenda Pirituba, realizando um levantamento para possível assentamento.

Esse processo enfrentou novos limites com o Golpe Militar de 1964, que:

[...] teve como decorrência a perda de uma das mais relevantes oportunidades de implementar a reforma. A sua realização nesta época teria como consequência importante efeito positivo no desenvolvimento econômico e social, em particular, beneficiaria o desenvolvimento da agricultura e o perfil de distribuição de rendas e riquezas (FERREIRA; ALVES; CARVALHO FILHO, 2009, p.157-158).

Em 1966, houve uma nova tentativa de regularização da situação dos pequenos agricultores rendeiros e dos pecuaristas. A proposta foi que cada família tivesse acesso a uma área de cem hectares, mas os pecuaristas não aceitaram. O Estado moveu, então, uma ação de despejo, mas os pecuaristas alegaram ter um contrato de arrendamento com o antigo preposto do Estado, Lino Vicenzi, e o poder judiciário acabou por Ihes conceder a posse da terra (COSTA, 2001).

O que se viu durante anos seguintes foi um amplo processo de grilagem das terras, de acordo com o interesse dos grandes proprietários e dos funcionários públicos responsáveis. Formaram-se grupos de proprietários que passaram a explorar a área; estes eram denominados como "holandeses" e "batagins", de acordo com a origem de suas famílias.

Com as irregularidades e o favorecimento aos grandes proprietários, apenas 27 famílias de pequenos agricultores foram beneficiadas, a partir da compra de suas parcelas, em um processo de loteamento chamado de Projeto Pirituba I (COSTA, 2001). Somente em maio de 1980 é que o Estado rescindiu o contrato de compromisso de venda firmado pelo antigo preposto e os holandeses e batagins e, então, realizou-se o despejo dos pecuaristas. Ao mesmo tempo, grupos de pequenos produtores rendeiros começaram a organizar uma ocupação para reivindicar as terras da fazenda Pirituba.

Diante da pressão dos agricultores, o Governo de Montoro (1983 a 1987) intervém e a ocupação da Fazenda Pirituba passou a ser tratada e conduzida como "questão agrária". Para Veiga (1990) citado por Bombardi (2005), o processo de negociação e regularização da área, a partir da ocupação camponesa, tardou a ocorrer. 
A retomada do processo partiu da ocupação do local por trabalhadores, que formariam o Movimento dos Trabalhadores Rurais Sem Terra (MST), o qual, graças à grande capacidade de mobilização de outros trabalhadores e ao apoio de Sindicatos Rurais, da Igreja Católica e de Prefeituras e Câmara Municipais da região, conseguiu criar um comitê que possibilitou uma maior pressão para regularizar a situação da fazenda Pirituba.

No fim do período da Ditadura Militar ocorreu o agravamento do conflito fundiário, como uma das consequências do processo de modernização conservadora da agricultura brasileira. Além das áreas tradicionais o recrudescimento do conflito acompanhou a expansão da fronteira agrícola. Paralelamente a estes fatos [...] crescia a organização dos trabalhadores expulsos da terra. A Comissão Pastoral da Terra - CPT foi criada em 1975 pela ala progressista do clero católico. O Movimento dos Trabalhadores Rurais Sem Terra - MST foi criado durante o primeiro Encontro Nacional dos Sem Terra, ocorrido em Cascavel de 20 a 22 de janeiro de 1984. Essa reunião contou com a presença de representantes de dezesseis estados. O Movimento não tem um dia de fundação, mas considera que nessa data começou a ser construído (FERREIRA; ALVES; CARVALHO FILHO 2009, p. 160).

Assim, as mesmas 250 famílias que ocuparam a área da fazenda Pirituba em 1981, com cerca de 1250 pessoas, mais tarde, acabaram por compor a organização do MST em nível nacional. Pode-se identificar, nesse processo, a formação de um movimento sócioterritorial territorializado, uma vez que:

\begin{abstract}
Os movimentos (socioterritoriais) territorializados são aqueles que atuam em diversas macrorregiões e formam uma rede de relações com estratégias políticas que promovem e fomentam a sua territorialização. Todos os movimentos territorializados começam como movimentos isolados. Estes ao se territorializarem e romperem com a escala local, se organizam em redes e ampliam suas ações e dimensionam seus espaços. A construção desses espaços e seus dimensionamentos são essenciais para as ações dos sujeitos que procuram transformar a realidade. Não existe transformação da realidade sem a criação de espaços (FERNANDES, 2005, p. 281).
\end{abstract}

Como a organização política dos sem-terra acabou por gerar conflitos, o Estado, por meio da Secretaria da Justiça e do Instituto de Assuntos Fundiários, conseguiu, judicialmente, o sequestro da área, conforme afirma Medici (1998) citado por Bombardi (2005).

A ocupação da área e o assentamento das primeiras famílias tiveram início, justamente, na porção da Fazenda que correspondia à dos chamados boiadeiros, herdeiros e beneficiários de Lino Vincezi, que continuaram na terra por mais de 20 anos após Lino ter sido indenizado pelo governo Carvalho Pinto. 
Posteriormente, as demais áreas griladas da fazenda Pirituba, ou seja, as que estavam sob o controle dos chamados holandeses e batagins - que não eram ocupantes da área, mas haviam adquirido as terras no processo de loteamento - passaram também a ser reivindicadas, e o mesmo sucedeu nas diferentes áreas de assentamentos do território em questão.

O processo de lutas e conquistas continuou com o assentamento de mais famílias nas áreas 3, 4, 5 e 6, nos anos de 1986, 1989, 1992 e 1996, respectivamente. Nestas novas áreas, foram sendo assentados filhos de pioneiros, em uma perpetuação da luta pela terra entre as gerações de camponeses que foram sendo forjadas. A violência por parte dos grandes produtores e a pressão ao Estado permearam todos esses processos de luta.

Esse processo demonstra que é o conflito, como expressão da luta de classes, que tem gerado, no Brasil, as políticas de reforma agrária, pois nunca foi o Estado que a implantou como um mecanismo de desenvolvimento econômico e social. Ao contrário, foi o campo conflitado que obrigou o Estado a implantar a reforma agrária. A reforma agrária é a apropriação de frações do território pelo campesinato, fruto da luta e do enfrentamento de classe levado a cabo por ele (BOMBARDI, 2005).

A resistência e a persistência camponesas territorializam-se quando os camponeses são assentados. Essa territorialização se dá de tal forma que frações do território se transformam em unidades territoriais camponesas, forjadas pela teia de parentesco, compadrio e vizinhança, que resultam na unidade e na "identidade territorial" expressas no modo como os camponeses se referem a eles próprios e a seus vizinhos. Essa unidade territorial é fruto da transformação dos assentamentos em bairros rurais (BOMBARDI, 2005, p. 687).

O território camponês, na fazenda Pirituba, conta, atualmente, com diversos sítios regularizados, em decorrência do primeiro processo de resistência iniciado em 1962, e com oito assentamentos conquistados a partir da luta engendrada após 1984.

Entretanto, como o território é dinâmico e se encontra em constante disputa, o conflito entre as classes sociais que se antagonizam não é superado com a conquista da terra. Esse conflito de interesses, no que tange, especificamente, à subordinação da renda camponesa ao capital, perdura. Perdura também a sanha pela apropriação da terra camponesa nas beiras da territorialização do capital monopolista (BOMBARDI 2005), como 
fica explícito na atuação de lojas de veneno, de atravessadores, do Estado, entre outros agentes externos.

No decorrer da década de 1990 e início do século XXI, o imperialismo passou a vestir a roupa do neoliberalismo, assim, a resistência camponesa foi desafiada pelo agronegócio e por seus pacotes tecnológicos e a juventude, influenciada pela ideologia globalizante, começou a abandonar o campo.

A contradição reside na resistência camponesa que persiste na região sudoeste paulista, a partir de ações desenvolvidas em busca da realização de uma efetiva Reforma Agrária, por meio de mobilizações por escolas, pela implementação de processos de cooperação e pela luta por condições melhores de vida e de trabalho.

\section{A organização do assentamento e o trabalho coletivo}

A organização dos primeiros assentamentos do PA Pirituba II ocorreu em um momento de grande efervescência da questão agrária brasileira, quando a Reforma Agrária era uma pauta constante. Neste contexto, envolveram-se diversos atores nas discussões acerca do assentamento, mas o protagonismo sempre foi dos trabalhadores; exemplo desta atuação foi a definição, em assembleia, dos critérios para o assentamento das famílias: só poderiam ser assentados trabalhadores sem-terra que não tivessem outra fonte de renda e que fossem, preferencialmente, casados.

Desde o início, a cooperação mostrou-se um fundamento na sociabilidade das famílias, como é propício nos acampamentos. Em sua maioria, os acampados eram camponeses expropriados de suas terras e a cooperação, para estes agricultores, possuía um forte aspecto cultural, expresso nos mutirões, na troca de dias trabalhados, na ajuda mútua.

Outro aspecto relevante foi a interferência de um Grupo Técnico ligado ao Estado, que incentivou a organização das famílias em uma associação. Os principais argumentos, para tal, referiam-se à necessidade de junção de esforços para o desmatamento, para a compra de máquinas e para o acesso a créditos na Caixa Econômica (COSTA, 2001).

O Estado, assim, assumiu o papel de induzir a criação de um instrumento jurídico, com a finalidade de realizar os financiamentos, mas também com a crença de que não seria possível aos agricultores produzirem em grande escala, individualmente, visto que o 
modelo de produção a ser adotado seria o de cultivo de grãos, nos moldes convencionais de uso de máquinas e insumos. Outro elemento, no que se refere ao papel do Estado, foi a exigência de participação nas assembleias, com base no argumento de que só haveria recursos para a produção se os assentados se organizassem, juridicamente, em uma associação.

A Associação dos Pequenos Produtores Rurais da Fazenda Pirituba, fundada pelas famílias, foi responsável por: discutir a organização das moradias em forma de agrovilas; realizar a distribuição dos lotes; comprar os primeiros equipamentos; e planejar a produção. Essa associação, em princípio, representava a organização das famílias da Agrovila I e da Agrovila II, mas logo foi desmembrada, por conta da distância, das dificuldades de comunicação entre as famílias das duas agrovilas e, por fim, pela diferente realidade produtiva que existia nas duas áreas.

Uma importante característica do PA Pirituba é que os assentamentos estão organizados em agrovilas: as famílias têm um lote de moradia de cerca de um hectare, assim, moram próximas umas das outras. Os lotes de produção, de cerca de 14 ha, ficam próximos das moradias, mas em espaço separado. Este modelo de organização contrapõese ao chamado "quadrado burro", onde os lotes são, simplesmente, recortados sem preocupação com a convivência das famílias e com os equipamentos públicos coletivos. No caso do PA Pirituba, todas as agrovilas preservam uma área social, de responsabilidade de todas as famílias.

Nos três primeiros anos de sua existência, a Associação da Agrovila I passou por fases distintas: no primeiro ano, houve uma produção muito boa, pois foram pagos todos os custos de produção e distribuídas as sobras; no segundo ano, não foi possível distribuir sobras; e, no terceiro, começaram a vencer as dívidas dos financiamentos e houve uma diminuição na colheita, o que causou endividamento.

A Associação da Agrovila I adiantava os recursos para a compra de insumos para a produção e para a alimentação dos associados, mas a situação de endividamento foi se agravando, o que levou muitos agricultores assentados a desistir do processo, perdendo, em Assembleia, o direito de continuarem no assentamento. Com medo de que a situação se repetisse, outros assentados permaneceram na associação, mas, por estarem descontentes, passaram a vender, paralelamente, sua produção, não cumprindo, desse 
modo, os acordos de pagamento de suas dívidas. A saída encontrada para controlar melhor a situação foi a formação de grupos de produção, mas esta estratégia não funcionou diante do alto endividamento dos sócios para com a associação e da associação para com os bancos.

Após muito tempo de discussão sobre como proceder para o pagamento da dívida das famílias, pois o patrimônio da entidade já não dava mais conta de pagar os compromissos assumidos, a Associação foi extinta. Embora essa situação de associativismo forçado, a partir da indução do Estado, tenha levado à criação e à extinção da associação, restaram os grupos de produção, cujas famílias, que tinham afinidades ou laços familiares, passaram a produzir coletivamente. Com os frutos do trabalho coletivo, os assentados criaram, então, duas cooperativas, a Cooperativa de Produção Agropecuária Coletiva (COPROCOL) e a Cooperativa 13 de maio.

O caso da Associação da Agrovila II não difere do da Agrovila I, em relação ao papel cumprido pelo Estado e ao endividamento das famílias, mas este grupo demorou mais para se organizar após o fim da Associação. Somente em 2005, eles passaram a se organizar em duas outras entidades, a COOPAFASP e a APALUFER, visando a desenvolver estratégias de comercialização coletiva, a partir do PAA e de um barracão. Outra característica relevante da Agrovila II é que, aos grãos, somaram-se o cultivo de frutas (ameixa, pêssego e cítricos) e legumes (principalmente quiabo), o que proporcionou maior diversidade produtiva.

Com a conquista parcial da área da Agrovila III, em 1986, as famílias organizaram-se para a produção coletiva na área emergencial, que ainda não correspondia aos 17 ha por família. Somente em 1996, os módulos foram completados e formaram-se três grupos que se organizaram em três locais de moradia distantes. Um dos grupos foi para uma área conhecida como Água Azul, outro, para a área que formou a COPAVA, e outro ocupou a área em que já havia algumas estruturas da fazenda.

Desses coletivos de produtores da Agrovila III, o único que resiste organizado com socialização completa dos meios de produção é a COPAVA, cujas famílias participantes compartilham terra, máquinas e implementos. São 27 famílias que se organizam em setores para a produção; o maior volume é na produção de grãos, mas eles também desenvolvem suinocultura, pecuária leiteira, cultivo de hortaliças e uma agroindústria para a fabricação de açúcar e cachaça. 
A ocupação da Agrovila IV aconteceu em outubro de 1989. Após uma série de despejos por parte do Estado, houve o assentamento emergencial de 48 famílias. Como na Agrovila III, a produção foi coletiva até que se completassem os módulos com a divisão da área, realizada pelo Estado. Após a divisão, parte dos assentados optou por produzir individualmente e parte formou a COPADEC, que acabou por se inviabilizar a partir de um financiamento feito via FEAP (Fundo de Expansão do Agronegócio Paulista). Atualmente, nesta Agrovila, há a produção coletiva de grãos em grupos familiares e/ou por afinidade e há, também, uma série de produtores individuais.

$\mathrm{O}$ caso da Agrovila $\mathrm{V}$ repete o histórico de cooperação das outras áreas. Enquanto eram assentadas emergenciais, as 44 famílias que ocuparam a área, em 1992, trabalhavam coletivamente. Com o parcelamento definitivo da área, 12 famílias optaram por trabalhar individualmente. Os assentados realizaram, ainda, uma discussão para destinar um espaço, de 13 hectares, para a construção da sede regional do MST e da COAPRI.

As famílias da Agrovila $V$, que permaneceram trabalhando coletivamente, formaram a COPANOSSA em 1994. Esta cooperativa adotou o modelo de produção que era recorrente na região, cuja estratégia em permanecer juntos estava ligada ao uso de alta tecnologia para produção em grande escala e para o acesso a créditos. A COPANOSSA financiou máquinas e implementos via PROCERA, mas quando chegou o tempo de pagar a dívida, os assentados não tinham recursos que não fossem o próprio investimento. Os sócios acabaram por se desfazer de toda a estrutura para o pagamento da dívida e, após o fazerem, houve uma negociação do MST com o governo, que amortizou grande parte do recurso devido. O estrago já estava feito, começaram os desentendimentos, a COPANOSSA se fragmentou e os sócios passaram a não realizar ações no âmbito da cooperativa.

Outra iniciativa de organização coletiva da Agrovila $V$ foi o grupo de mulheres para trabalhar com plantas medicinais. Este mesmo grupo passou por diversas tentativas de organização para a produção de doces e produtos fitoterápicos e, atualmente, as mulheres estão organizadas na COOPLANTAS, que envolve assentadas das Agrovilas II, III, V e VI. As companheiras fazem um amplo debate sobre gênero, agroecologia e saúde, apropriandose das discussões feitas pelo MST, trabalhando com medicina preventiva e desenvolvendo projetos que visam a garantir a geração de renda para as mulheres. 
As famílias da Agrovila $V$, atualmente, organizam-se para o desenvolvimento de práticas de esporte, principalmente, os homens, para jogos de futebol e para a realização de uma festa anual para a construção da Igreja Católica do assentamento. Há, ainda, poucos grupos familiares que atuam na produção coletiva.

A Agrovila VI, por sua vez, originou-se de uma ocupação realizada em 1994; o assentamento também se deu em situação emergencial e, somente, no ano de 2013, parece que o ITESP faria a regularização para completar os módulos dos lotes (17 anos se passaram). Após muitas dificuldades para garantir condições de vida digna, como moradia e água encanada, as famílias conseguiram, em 2008, concluir a construção das casas, também organizadas por proximidade. A experiência de cooperação deu-se com a Cooperativa Chico Mendes, que trabalhava, informalmente, até se tornar associação. Os assentados também começaram a produção de forma coletiva, mas acabaram por individualizar-se. Atualmente, as famílias atuam coletivamente no que se refere a um caixa único para a manutenção da rede de água e para as atividades da Igreja, como bailes e festas beneficentes em prol da construção da Igreja Católica na área coletiva.

Ao mesmo tempo em que se desenvolviam os assentamentos, os pequenos produtores da região enfrentavam dificuldades para permanecer no campo por não conseguirem acompanhar o processo acentuado de mudança tecnológica, que não considera as especificidades da agricultura familiar. Estes se encontravam cada vez mais endividados e, como as necessidades aumentavam, muitos chegaram a vender as terras para pagar dívidas e, na maioria das vezes, migraram para o meio urbano.

Em 1995, assentados e pequenos produtores discutiram, conjuntamente, a possibilidade de viabilizar uma cooperativa para garantir acesso ao mercado, por meio da organização da produção e da comercialização desta através da estrutura coletiva. Tal iniciativa possibilitou que os produtos dos assentados e pequenos agricultores ganhassem melhor preço e não se perdessem. Neste contexto, criar uma estrutura que abarcasse tais demandas foi uma questão de necessidade para buscar alternativas que possibilitassem a permanência das famílias assentadas e dos pequenos agricultores no campo.

Assim, em outubro 1996, fundou-se a Cooperativa de Assentados de Reforma Agrária e Pequenos Produtores da Região de Itapeva - COAPRI, cuja principal atribuição foi criar estratégias de articulação com as várias cooperativas, associações e grupos de produção 
dos assentados e dos pequenos agricultores da região, com o objetivo de possibilitar uma ação conjunta em casos de reivindicação e defesa dos interesses comuns.

Ao longo de sua história, a COAPRI vem desenvolvendo iniciativas pautadas em princípios de cooperação, respeito ao meio ambiente e beneficiamento da produção e do comércio justo, a partir da consolidação e do fortalecimento das linhas de produção de grãos, leite, verduras, legumes e frutas.

Em 13 de maio de 2011, após, exatamente, 27 anos da ocupação que deu origem às Áreas I e II, filhos de assentados da Agrovila II ocuparam uma área da fazenda Pirituba, ainda explorada, irregularmente, por um pecuarista. Em 2013, o ITESP realizou o assentamento emergencial de 23 famílias, o que comprovou a possibilidade de conquista de novas áreas.

De qualquer forma, dos 17.420 hectares da Fazenda Pirituba, mais de 8 mil hectares, que eram explorados, irregularmente, por grileiros, passaram ao controle dos agricultores assentados. Há ainda a área de um horto florestal, pertencente ao Estado, e áreas regularizadas pelo PA Pirituba I. A área de horto, segundo o Estado, não é passível de realização de assentamento, devido a um contrato de extração de resina de Pinus, estabelecido com uma empresa privada, impossível de ser quebrado, pois está ali atua há muitos anos.

Transcorridos quase 30 anos, começaram a aparecer sinais de inadequação do modelo de produção, uma vez que a única possibilidade imposta pelo Estado foi o incentivo às monoculturas de grãos, como feijão, milho e soja, todas com alto grau de dependência de empresas de vendas de insumos e de atravessadores para o mercado. Os agricultores assentados conseguiram se aproximar do padrão de agricultura regional, no entanto, o cultivo, principalmente, de milho e feijão, em áreas, geralmente, inferiores a 15 hectares, não tem sido suficiente para a obtenção de um patamar de renda que permita um padrão de vida mais confortável e seguro para os agricultores e suas famílias.

A contradição está posta pela pressão exercida pela monocultura de grãos e pelo uso intensivo de produtos químicos na prática agrícola, fomentados pela presença contundente de técnicos de lojas de veneno que acabam por realizar a "assistência técnica" aos trabalhadores assentados. 
Na região, costuma-se adotar o cultivo de até três tipos de grãos em um mesmo ano. As lavouras de milho, trigo e feijão sucedem-se de forma a manter altos índices de produção nas áreas do assentamento e dos pequenos agricultores. Segundo dados da COAPRI, foram produzidos, somente no PA Pirituba II, aproximadamente, 10.000 toneladas de milho, 3.000 toneladas de feijão e 2.400 toneladas de trigo, durante a safra 2010/2011. Entretanto, na safra 2011/2012, iniciou-se um processo de concorrência entre as lavouras de feijão e soja, pelo alto preço pago pela soja, chegando-se à produção de 1.200 toneladas de feijão. Já na safra 2012/2013, a situação foi agravada pela postura das lojas que financiam os insumos, que assumiram o cultivo de feijão como "lavoura de risco". Muito provavelmente, o risco refere-se à possibilidade dos agricultores em acessar as sementes via COAPRI, a partir da doação via CONAB, como vem acontecendo desde 2010. O fornecimento das sementes quebra a lógica da dependência em relação aos outros insumos, ou seja, as empresas de insumos perdem o controle do que está sendo plantado e do que vai ser colhido.

\section{A organização do assentamento entre 2003 e 2013}

Em 2003, o Governo Federal passou a executar o II Plano Nacional de Reforma Agrária, que teria, entre seus objetivos, a retomada dos investimentos nos assentamentos rurais. O INCRA passou a atuar na região e a discutir o Plano de Recuperação dos Assentamentos (PRA), acompanhado pela direção do MST, que aposta no projeto. Segundo documento publicado por técnicos do órgão, o PRA:

[...] tinha por objetivo garantir que o Projeto de Assentamento (PA) atinja o nível desejado de desenvolvimento sustentável - garantindo crescimento da renda, geração de empregos, aumento da produção e das condições de cidadania visando sua consolidação e tendo como perspectiva o desenvolvimento territorial integrado, resultantes das políticas governamentais e das parcerias institucionais (BEZE et al., 2005, p. 237).

O diagnóstico feito com a participação dos assentados apontava que os agricultores enfrentavam problemas para a obtenção de recursos financeiros, principalmente, pela pouca diversidade produtiva nos cultivos que geravam renda. A maior parte dos agricultores realizava cultivos de grãos, especialmente, de milho e feijão, em pequenas 
áreas, utilizando o padrão tecnológico do grande agronegócio, ou seja, com um alto custo de produção.

Em que pese a alta produtividade, tais culturas caracterizam-se por: alto nível tecnológico empregado, intensivo uso de insumos e baixo índice de geração de emprego e renda no campo. Pode-se observar altos custos de produção devido à dependência de energia externa e ao uso de máquinas pesadas e de fertilizantes químicos e pesticidas, ou seja, pela adoção do modelo forjado para o agronegócio exportador.

A desvalorização da produção ocorre também devido à dependência dos agricultores dos insumos comercializados por lojas agropecuárias da região e à "assistência técnica" ofertada por tais empresas. Estas adotam uma política de compra dos grãos produzidos para a quitação das dívidas dos agricultores, o que diminui ainda mais os preços praticados no mercado local.

Nesse contexto, a realidade de endividamento era clara e aumentava a dependência dos agricultores em relação aos fornecedores de insumos:

\begin{abstract}
A situação do crédito é muito grave, caracterizando-se pela ocorrência de elevado grau de inadimplência e consequente dificuldade de acesso ao crédito bancário. Este fato é especialmente severo junto ao Banco Nossa Caixa, sem perspectiva de renegociação coletiva. A inadimplência implica em outras formas de créditos juntos a fornecedores de insumos - muitas vezes com empenho de bens - altamente prejudiciais para os produtores. Para os que não dispõe de garantias e estão inadimplentes, há ocorrência de assalariamento da mão-deobra familiar e arrendamento de parte do lote (BEZE, et al, 2005, p.239)
\end{abstract}

Além dessa situação de endividamento em relação ao Banco, em 2003, as famílias assentadas acessaram o Programa Compra Antecipada, gestado pela Companhia Nacional de Abastecimento, que consistia na liberação de recursos para entrega futura de milho. Em um primeiro momento, o recurso foi distribuído, individualmente, aos assentados, na entressafra, mas muitos não conseguiram cumprir o contrato e tornaram-se inadimplentes. Em um segundo momento, a COAPRI acessou o recurso e comprou insumos para fornecer aos assentados, e estes passaram a dever também para a cooperativa regional.

Outra questão relevante é a insuficiência da assistência técnica de responsabilidade do ITESP. Os agricultores dependem do órgão para encaminhar os projetos de acesso a créditos, como o PRONAF, mas estes, muitas vezes, foram liberados com atraso, ou seja, fora da época de plantio. 
Para a superação dessa realidade, iniciou-se um amplo processo de discussão com os assentados, respeitando as organizações de cada comunidade. Montou-se, em parceria com os técnicos do INCRA/MDA e com acompanhamento da direção do MST, o Fórum dos Assentados, em que foram apontadas as demandas para a garantia da melhoria de renda dos agricultores assentados.

Desse processo resultou uma retomada da COAPRI, com melhores definições acerca das linhas de produção a serem potencializadas para a diversificação. Estas linhas, discutidas com os associados da COAPRI, devem cumprir o papel de garantir a produção integrada entre campo e agroindústria, de modo a construir um ciclo produtivo baseado nas cadeias produtivas de grãos, leite e hortifrutigranjeiros. Ao potencializar estes ciclos produtivos a partir do beneficiamento em agroindústrias, buscou-se garantir melhorias na renda e a construção da soberania das famílias assentadas e dos pequenos produtores, além de fortalecer uma produção com práticas agroecológicas.

Com base na aptidão produtiva da região, os assentamentos têm sido fortes produtores de grãos e, nos últimos anos, a COAPRI tem garantido os valores máximos de comercialização com o governo federal. Na safra 2010/2011, foram comercializados $R \$ 1,3$ milhões com a CONAB, totalizando $800.000 \mathrm{~kg}, 30 \%$ a mais do que na safra 2009/2010. No âmbito do PNAE, foram fechados, em 2011, contratos com 5 prefeituras, que totalizaram $250.000 \mathrm{Kg}$. O desafio é garantir a transição agroecológica das lavouras, reduzindo o uso de agrotóxicos, de modo a possibilitar uma produção mais saudável e mais barata, pela diminuição da dependência das grandes empresas.

No caso da produção de leite, a principal ação refere-se à estruturação do Laticínio "Raízes da Terra", que é uma microusina de processamento de leite que foi construída em uma parceria entre a COAPRI, o INCRA/MDA e a Prefeitura Municipal de Itapeva. Foi uma demanda concretizada a partir de discussões entre os assentados da Fazenda Pirituba II, como alternativa à monocultura de grãos. O laticínio pode processar 5.000 litros de leite por dia, além de produzir queijos, do tipo mozarela, minas frescal, minas padrão, prato, coalho e purunguinha, e Bebida Láctea, logurte e Leite Pasteurizado Tipo C. No ano de 2012, o laticínio atendeu as Prefeituras de Itaberá e Bom Sucesso de Itararé, no Programa de Alimentação Escolar, e entidades beneficentes do Município de Itapeva, via Programa Doação Simultânea, além de comercializar os produtos no mercado local. 
Já em relação à produção de verduras, legumes e frutas, com a concretização do Programa de Aquisição de Alimentos (PAA), houve um grande impulso à produção e à comercialização de hortifrutigranjeiros. Esse aumento foi de $40 \%$ em três anos. Foi realizada uma parceria com a BIONATUR e sementes de hortaliças foram disponibilizadas, além disso, a COAPRI pôde garantir algumas estruturas que viabilizaram essa comercialização, como caixas, balanças, transporte, entre outros.

As formas encontradas pela Cooperativa Regional para superar problemas foram: 0 incentivo à diversificação da produção e a busca por alternativas de comercialização que melhorassem os preços ofertados aos grãos produzidos. Todas as demandas das famílias assentadas assumiram um caráter reivindicatório a partir das diversas lutas empreendidas pelo MST, que resultaram em algumas conquistas, entre elas, as políticas públicas de comercialização. Tais políticas têm mostrado um caminho de possibilidades que acabam por não submeter a produção dos agricultores assentados à lógica do mercado, imposta pelos atravessadores.

As iniciativas de comercialização concretizaram-se, principalmente, no âmbito institucional, por meio do acesso ao Programa de Aquisição de Alimentos e ao programa Aquisição do Governo Federal, realizados pela Companhia Nacional de Abastecimento (CONAB) e pelo Programa Nacional de Alimentação Escolar (PNAE), que garantem preços mais justos para a produção de grãos e proporcionam maior diversificação na produção de hortifrutigranjeiros, maior renda às famílias assentadas e aos pequenos produtores e acesso a alimentos de qualidade aos que (sobre)vivem em condições de insegurança alimentar.

\section{O Programa de Aquisição de Alimentos (PAA)}

O PAA é uma iniciativa do Programa Fome Zero que vem sendo acessado pelas famílias do PA Pirituba II desde 2007. Este programa é uma ação interministerial, que envolve os ministérios da Agricultura, Pecuária e Abastecimento (MAPA), do Desenvolvimento Agrário (MDA) e do Desenvolvimento Social (MDS). Divide-se em duas modalidades: Doação Simultânea e Formação de Estoques. 
Na modalidade Doação Simultânea, os assentados têm o direito de entregar até $\mathrm{R} \$ 4.800,00$ por ano a entidades beneficentes articuladas pela COAPRI, que se responsabiliza por prestar contas à CONAB e fazer o pagamento aos produtores.

Com o PAA, a produção dos quintais dos assentamentos passou a ter valor de troca, e cada um dos frutos colhidos, além de alimentar as famílias assentadas, passou a fazer parte do cardápio de trabalhadores do meio urbano que (sobre) viviam em condições de insegurança alimentar. Abriu-se, assim, um canal de diálogo com a sociedade, que pôde conhecer a produção dos assentamentos.

Destaca-se, ainda, no PAA - Doação Simultânea, a participação das mulheres dos assentamentos, que, muitas vezes, são as responsáveis pelo cultivo dos quintais e pela diversificação crescente que pode ser notada nos lotes de produção, principalmente, a partir da implantação de pomares de fruticultura, com banana, pêssego, ameixa, uva, entre outras espécies.

A conflitualidade expressa-se na disputa pelo controle político do programa, uma vez que, ao perceber a importância política desse movimento social, o Estado, na figura do INCRA, passa a disputar a organização das famílias assentadas, criando novos instrumentos jurídicos, cooperativas e associações, responsáveis por descentralizar o projeto.

De qualquer maneira, o que se tem percebido é que essas estratégias de descentralização também enfrentam problemas, pois as novas entidades, muitas vezes, não têm mecanismos de gestão de projetos e de discussão mais aprofundada com os agricultores, inviabilizando-se ao longo do tempo.

No caso da modalidade Formação de Estoques, pôde-se garantir, desde 2007, preços melhores ao feijão produzido nos assentamentos. A CONAB disponibiliza recursos mediante a apresentação de um projeto por parte da cooperativa. Os recursos podem vir do MDS ou do MDA e os agricultores podem entregar até $\mathrm{R} \$ 8.000,00$ por ano.

Para os recursos oriundos do MDS, o pagamento do projeto deve ser feito, necessariamente, em produtos, que devem compor a cesta básica. Na safra 2010/2011, a COAPRI comercializou 800 toneladas de feijão, que foram empacotados com a marca "Raízes da Terra - Produto da Reforma Agrária" e distribuídos em cestas básicas durante os anos de 2011 e 2012. 
Nessa mesma safra, a Cooperativa regional pagou aos produtores o valor de $\mathrm{R} \$ 87,60$ por saca de $60 \mathrm{Kg}$, enquanto os atravessadores pagavam apenas $\mathrm{R} \$ 40,00$ por saca. Para se ter ideia da exploração, o custo de produção de uma saca de feijão chega a $\mathrm{R} \$ 60,00$, segundo dados do Banco do Brasil.

Já no caso dos recursos oriundos do MDA, a cooperativa pode pagar o projeto em dinheiro ou em produto, o que serve, então, para a formação de um capital de giro, que assegura a compra da safra por um preço justo e a venda, na entressafra, por um preço melhor.

\section{O Programa Nacional de Alimentação Escolar (PNAE)}

O Programa Nacional de Alimentação Escolar foi criado em 2010 e este prevê que, de todo o recurso repassado pelo Fundo Nacional de Desenvolvimento da Educação (FNDE) para as prefeituras, para que estas comprem alimentos para fornecimento nas escolas, $30 \%$ deve ser gasto com compras diretas da Agricultura Familiar.

Desde 2011, a COAPRI participa das chamadas públicas para entrega de feijão e derivados de leite beneficiados pela Cooperativa. Neste caso, o preço, normalmente, é o preço de mercado. Se, no caso de Formação de Estoques, a saca de feijão é comercializada

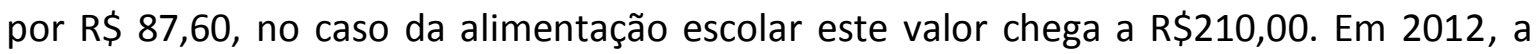
COAPRI forneceu 240 mil $\mathrm{Kg}$ de feijão para oito prefeituras.

As conflitualidades, nesse caso, expressam-se: pela negligência de algumas prefeituras em cumprir a legislação; pela presença de uma estrutura de mercado, muitas vezes, duvidosa, que atende a demanda das prefeituras; e pela apropriação, por parte de empresas do agronegócio, que alegam estar trabalhando com agricultores familiares.

\section{Considerações finais}

O desenvolvimento do modo de produção capitalista no campo tem levado muitos autores a acreditar no fim do campesinato, mas a realidade, do lado de fora da academia, mostra que a luta pela terra e pela sobrevivência no campo tem gerado conflitos constantes que são o retrato de uma resistência de classe. 
A conflitualidade e o desenvolvimento acontecem simultâneos e consequentemente, promovem a transformação de territórios [...]. A agricultura camponesa estabelecida ou que se estabelece por meio de ocupações de terra e implantação de assentamentos rurais, resultantes de políticas de reforma agrária, promovem conflitos e desenvolvimento. [...] uma parte fundante desse paradoxo é a obsessão da destruição do campesinato e no crescimento da organização camponesa em diferentes escalas e de diversas formas [...]. (FERNANDES, 2008, p. 6).

Acreditar nessa resistência e avançar na organização dos trabalhadores é o desafio que está posto, pois, segundo Fernandes (2008, p. 3), “ao conquistarem a terra, ao serem assentadas," a famílias "não produzem apenas mercadorias, criam e recriam igualmente a sua existência."

Neste contexto, Fernandes, Welch e Gonçalves (2011, p. 38) afirmam ainda que:

A continuidade da hegemonia do agronegócio projeta o maior enfraquecimento do campesinato com o aumento do número de agricultores com renda insuficiente para sua sobrevivência. [...]. O aumento do poder político do campesinato pelo fortalecimento de suas organizações e maior apoio da sociedade civil pode mudar o rumo do atual modelo de desenvolvimento do campo brasileiro, com a ampliação da participação da produção da agricultura familiar no valor bruto da produção [...].

Ao se acreditar em uma possível transformação da sociedade e que a resistência dos trabalhadores é uma saída, acaba-se por vislumbrar possibilidades concretas de transformação. Embora este seja um caminho tortuoso em que as contradições afloram, há conquistas que revelam os conflitos e refletem a necessidade de se avançar rumo a uma maior consciência para a emancipação da classe. E esse não será um processo rápido...

"Através do controle político, o Estado pode mudar o rumo das ações dos movimentos camponeses: fazê-lo refluir e até desmobilizá-los. Ainda assim o problema agrário continua." (FERNANDES, 2008, p. 47).

\section{Referências}

BERBEROGLU, B. Centralidad de la clase en los estudios críticos del desarrollo. In: VELTMEYER, H. (Org.). Herramientas para el cambio: manual para los estudios críticos del desarrolo. Universidad Mayor de San Andres: Plural, 2011. p. 143-148.

BEZE, Z. et al. Processo de discussão e implementação do Plano de Recuperação do PA Pirituba II. In: FERRANTE, V.L.S.B., ALY JUNIOR, O. (Orgs). Assentamentos Rurais: Impasses e Dilemas (uma trajetória de 20 anos). São Paulo: Instituto Nacional de Colonização e Reforma Agrária Superintendência Regional de São Paulo, 2005. p.237-254. 
BOMBARDI, L. M. Campesinato, luta de casse e reforma agrária (a lei de revisão agrária em são Paulo). 2005. Tese (Doutorado em Geografia Humana) - Departamento de Geografia, Faculdade de Filosofia, Letras e Ciências Humana, Universidade de São Paulo, São Paulo, 2005.

COSTA, C.M.O. Processo organizativo em assentamentos rurais: um olhar sobre a fazenda Pirituba.2001. 143f. Dissertação (Mestrado em Engenharia Agrícola) - Faculdade de Engenharia Agrícola, Universidade Estadual de Campinas, Campinas, 2001

FERNANDES, B. M. Movimentos socioterritoriais e movimentos socioespaciais: Contribuição teórica para uma leitura geográfica dos movimentos sociais. En: OSAL : Observatorio Social de América Latina. Año 6 no. 16 (jun. 2005- ). Buenos Aires : CLACSO, 2005 p. 273-284.

FERNANDES, B. M. Questão agrária: conflitualidade e desenvolvimento territorial. In: BUAINAIN, A. M. (Org.). Luta pela terra, reforma agrária e gestão de conflitos no Brasil. Campinas: Ed. Unicamp, 2008. p. 173-224.

FERNANDES, B. M.; WELCH, C. A.; GONÇALVES, E. C. G. Questão agrária e disputas territoriais no Brasil. Presidente Prudente, 2011. Inédito.

FERREIRA, B. A reforma agrária no governo Lula, balanço 2003-2005. In: Revista da Associação brasileira de reforma agrária (ABRA). Vol.32. ago/dez, 2005

FERREIRA, B.; ALVES, F.; CARVALHO FILHO, J.J. “Constituição Vinte Anos: Caminhos e descaminho da Reforma Agrária - Embates (permanentes), Avanços (Poucos) e Derrotas (muitas)". IPEA: Acompanhamento e Análise - Vinte anos de Constituição Federal. IPEA, BPS 17. Vol.2, Cap. 3, pp.155-223. Brasília - DF, 2009.

HOFLING, E.M. Estado e políticas (públicas) sociais. Cad. CEDES [online]. 2001, vol.21, n.55, pp. 3041. ISSN 0101-3262. http://dx.doi.org/10.1590/S0101-32622001000300003.

KAUTSKY, K. A questão agrária. Portugal: Proposta, 1980.

LÊNIN, V. I. Estado e revolução. São Paulo: Expressão Popular, 2003.

MARX, K. O capital: crítica da economia política: livro I. Rio de Janeiro: Civilização Brasileira, 2004.

MÈSZAROS, I. O desafio e o fardo do tempo histórico. São Paulo: Boitempo, 2011.

OLIVEIRA, A. U. Modo de produção capitalista, agricultura e reforma agrária. São Paulo: FFLCH, 2007.

OLIVEIRA, B. A. C. C. Tempo de travessia, tempo de recriação: profecia e trajetória camponesa. 1998. Tese (Doutorado em Antropologia Social) - Departamento de Antropologia, Faculdade de Filosofia, Letras e Ciências Humanas, Universidade de São Paulo, São Paulo, 1998. 
PETRAS, J. Poder y desarrollo: la política del império. In: VELTMEYER, H. (Org.). Herramientas para el cambio: manual para los estudios críticos del desarrolo. Universidad Mayor de San Andres: Plural, 2011. p. 149-154.

PETRAS, J.; VELTMEYER, H. Los campesinos y el estado en América: un pasado turbulento, un futuro incierto. Problemas del Desarrollo, México, v. 34, n. 131, p. 7-64, 2003.

RAFFESTIN, C. Por uma geografia do poder. Tradução de Maria Cecília França. São Paulo: Ática, 1993.

THOMAZ JÚNIOR, A. Dinâmica geográfica do trabalho no século XXI (limites explicativos, autocrítica e desafios teóricos). 2009. Tese (Livre Docência em Geografia) - Faculdade de Ciências e Tecnologia, Universidade Estadual Paulista, Presidente Prudente, 2009.

. Geografia e trabalho no século XXI. Presidente Prudente: Centelha, 2004.

. O trabalho como elemento fundante para compreensão do campo no Brasil. Candeia, Goiânia, v. 4. p. 51-60, 2002. 